\title{
man \\ COVID-19 in a Neuroimmunological Outpatient Cohort: The Bernese Experience
}

\author{
Maximilian Pistor*D, Anke Salmen, Andrew Chan and Robert Hoepner
}

check for updates

Citation: Pistor, M.; Salmen, A. Chan, A.; Hoepner, R. COVID-19 in a Neuroimmunological Outpatient Cohort: The Bernese Experience. Clin. Transl. Neurosci. 2022, 6, 6. https:// doi.org/10.3390/ctn6010006

Academic Editors: Claudio Bassetti and Dominik Straumann

Received: 25 October 2021 Accepted: 10 February 2022 Published: 16 February 2022

Publisher's Note: MDPI stays neutral with regard to jurisdictional claims in published maps and institutional affiliations.

Copyright: (C) 2022 by the authors. Licensee MDPI, Basel, Switzerland. This article is an open access article distributed under the terms and conditions of the Creative Commons Attribution (CC BY) license (https:// creativecommons.org/licenses/by/ $4.0 /)$.
Department of Neurology, Inselspital, Bern University Hospital, University of Bern, CH-3010 Bern, Switzerland; anke.salmen@insel.ch (A.S.); andrew.chan@insel.ch (A.C.); robert.hoepner@insel.ch (R.H.)

* Correspondence: maximilian.pistor@insel.ch

\begin{abstract}
The COVID-19 pandemic specifically affects the management and treatment of patients with autoimmune neurological disorders. Major concerns include potentially higher risks of infection or severe disease course under certain immunotherapies used to treat those disorders and the influence of COVID-19 on the underlying disease. We present data of the neuroimmunological outpatient department of the University Hospital of Bern (Switzerland). 24 cases were analyzed, 19 of them suffered from Multiple Sclerosis. Of these 24 patients, 6 were hospitalized, 2/ 6 were treated in the Intensive Care Unit. Possible risk factors for severe course (defined as need for hospitalization) observed in our cohort included cardiovascular risk factors, treatment with B-cell depleting agents, Sphingosine-1 Phosphate Receptor Modulators, and oral steroid therapies. These data are based on a small, retrospective observational cohort and should be interpreted with caution, although they are in line with several other cohort studies.
\end{abstract}

Keywords: COVID-19; SARS-CoV-2; multiple sclerosis; NMOSD; Myasthenia Gravis; immunotherapies

\section{Introduction}

COVID-19 caused by SARS-CoV-2 substantially impacts surveillance and treatment of people with autoimmune neurological disorders like Multiple Sclerosis (MS). Since most of the treatments, herein referred to as immunotherapies, change function and constitution of the immune system, questions about infectious risks of these agents in times of COVID-19 arise. The evidence on these topics has previously been sparse, and to a certain degree still is today. Early registry studies in MS and rheumatological patient cohorts during the pandemic identified possible factors enhancing morbidity, namely age, male sex, B-cell depleting- and steroid therapies [1-5]. Our retrospective study, using the international, open-access database "FDA Adverse Events Reporting System" (FAERS) and including data on the course of the pandemic and the abilities of the respective healthcare systems, demonstrated age, male sex and B-cell depleting therapies as mortality risk enhancing factors [6]. Larger efforts such as the Neuro-COVID registry "EAN NEuro-COVID ReGistrY Consortium" (ENERGY) of the European Academy of Neurology (EAN) and the "Lean European Open Survey on SARS-CoV-2 infected patients" (LEOSS)-registry [7,8], in which Bern alongside with several Swiss and German centers participated, are ongoing $[9,10]$. The aim of the data presented here is to demonstrate the impact of COVID-19 on a university neuroimmunological outpatient department, to describe risk factors (with regard to patients and in relation to immunotherapy) and the short-term impact of COVID-19 on the underlying disorder.

\section{Materials and Methods}

This single-center, observational, retrospective cohort study of patients from the Bern University Hospital neuroimmunological outpatient department includes male and female adult patients with any neuroimmunological disease with PCR-confirmed infection 
with SARS-CoV-2 between March 2020 and May 2021. Anecdotal cases without PCR confirmation $(n=3)$, and cases with missing information $(n=2)$ were excluded. The development of anti-SARS CoV-2 antibodies in COVID-19 patients treated with B-cell depleting therapies was recently described using this cohort by Friedli et al. [11].

Data were analyzed with SPSS (C) Statistics 25 (IBM Armonk, New York, NY, USA, 2017). Figures were prepared with Graphpad Prism 8 (San Diego, CA, USA, 2018). All patients gave written informed consent to participate in the neuroimmunological registry (KEK BE 2017-01369).

\section{Results}

\subsection{Patient Cohort}

This cohort consists of patients from within the Bern University Hospital (Switzerland) neuroimmunological outpatient department $(n=24)$. The mean age of our patients is 45.0 years (Range: 25-67, 95\%-confidence interval (95\% CI): 40.1-49.8) with 17/24 being female. Most patients in our cohort suffer from MS $(n=19)$, mostly of a relapsing-remitting phenotype $(n=17)$, Myasthenia Gravis (MG, $n=2)$, Neuromyelitis-Optica Spectrum Disorder (NMOSD, $n=1)$, Behçet's Disease $(n=1)$ and one case of "Progressive Encephalomyelitis with Rigidity and Myoclonus" (PERM, $n=1)$. Within the MS and NMOSD subcohort, the mean Extended Disability Status Scale (EDSS) before COVID-19 was 2.4 (95\% CI: 1.3-3.5; range $0-7) .8 / 24$ of patients were, at the timepoint of their infection, treated with B-cell depleting agents (Ocrelizumab 6/24 and Rituximab 2/24), followed by Sphingosine-1 Phosphate Receptor Modulators (S1PRM, Fingolimod 4/24 and Ozanimod 1/24); the other immunotherapies are listed in Table 1. Prednisolone is used in 2 patients, in conjunction with Azathioprine or Rituximab, respectively, at a Prednisolone dose of $5 \mathrm{mg} /$ day.

Table 1. Characteristics of our patient cohort.

\begin{tabular}{|c|c|c|}
\hline Category & Subcategory & $n$ \\
\hline \multirow[t]{2}{*}{ Sex } & Male & $7 / 24$ \\
\hline & Female & $17 / 24$ \\
\hline Age & & $\begin{array}{c}\text { Mean } 45.2 \text { (Range: } 25-67,95 \% \text { CI: } \\
40.2-50.3 \text { ) }\end{array}$ \\
\hline \multirow[t]{8}{*}{ Diagnosis } & MS & $19 / 24$ \\
\hline & RRMS & $17 / 19$ \\
\hline & SPMS & $1 / 19$ \\
\hline & PPMS & $1 / 19$ \\
\hline & MG & $2 / 24$ \\
\hline & NMOSD & $1 / 24$ \\
\hline & Neuro-Behçet's Disease & $1 / 24$ \\
\hline & PERM & $1 / 24$ \\
\hline Disability Status (MS- and & & Mean EDSS 2.4 (Range: 0-7.0, 95\% \\
\hline NMOSD patients) & & CI 1.3-3.5) \\
\hline \multirow[t]{11}{*}{ Immunotherapy } & No immunotherapy & $4 / 24$ \\
\hline & Azathioprine & $2 / 24$ \\
\hline & Prednisolone ${ }^{1}$ & $2 / 24$ \\
\hline & Dimethyl Fumarate & $2 / 24$ \\
\hline & IFN-Beta & $1 / 24$ \\
\hline & IVIG & $1 / 24$ \\
\hline & Fingolimod & $4 / 24$ \\
\hline & Natalizumab & $1 / 24$ \\
\hline & Ocrelizumab & $5 / 24$ \\
\hline & Ozanimod & $1 / 24$ \\
\hline & Rituximab & $2 / 24$ \\
\hline Cardiovascular Risk Factors ${ }^{2}$ & & $11 / 24$ \\
\hline
\end{tabular}

Abbreviations: EDSS: Extended Disability Status Scale, RRMS-relapsing-remitting Multiple Sclerosis (MS), SPMS: secondary-progressive MS, PPMS: primary-progressive MS, NMOSD: Neuromyelitis Optica Spectrum Disorder, MG: Myasthenia Gravis, PERM: Progressive Encephalomyelitis with Rigidity and Myoclonus. ${ }^{1}$ In conjunction with Azathioprine and Rituximab in 1 case, each. Dose in both cases $5 \mathrm{mg} /$ day. ${ }^{2}$ Cardiovascular Risk Factors: Arterial Hypertension (4/24), Dyslipidemia (3/24), Diabetes Mellitus Type 2 (3/24), Obesity (3/24), Smoking (4/24), more than one might be present. 
Concomitantly, 11/24 patients presented with cardiovascular risk factors, including arterial hypertension (4/24) and diabetes mellitus type 2 (3/24). Cardiovascular risk factors are present in $4 / 6$ of the hospitalized patients.

\subsection{COVID-19 Course}

Following the course of the pandemic, most SARS-CoV-2 infections occurred between September 2021 and February 2022 (19/24; see Figure 1), when most infections in Switzerland also occurred [12].

\section{COVID-19 cases}

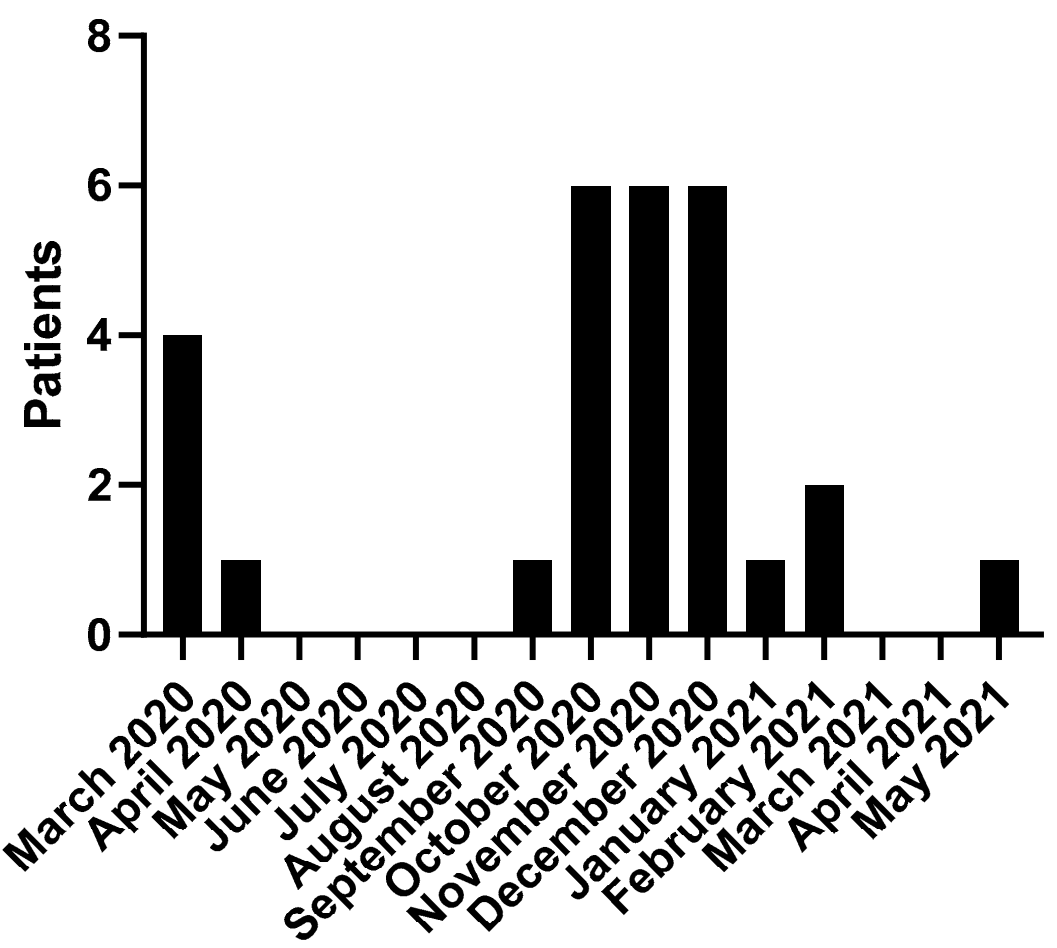

Figure 1. Showing the COVID-19 cases per month of our cohort.

In $18 / 24$ cases, the disease course was mild with patients being managed in an outpatient setting and with symptomatic treatment only, if any. No deaths were observed, but 6/24 patients were hospitalized. One MS patient (treated with Fingolimod) and one MG patient (treated with Rituximab plus Prednisolone) suffered from viral Acute Respiratory Distress Syndrome (ARDS) and both were transferred to an Intensive Care Unit (ICU). The antiviral drug Remdesivir [13] was administered in 2 cases (in one hospitalized- and in one ICU patient) and Dexamethasone in 3 (in two ICU patients and one hospitalized patient) in conjunction with supplementary oxygen [14] (see Table 2). Within the six hospitalized patients, three were treated with B-cell depleting agents (1/3 Rituximab, 1/3 Ocrelizumab, 1/3 Rituximab plus Prednisolone), two with S1PRM (Fingolimod and Ozanimod $n=1$ each) and one with Azathioprine plus Prednisolone for their underlying autoimmune disorder.

\subsection{Influence of COVID-19 on Underlying Disease}

Since our cohort mainly consists of MS patients, we will briefly discuss the impact of COVID-19 on their underlying disease. One relapse post COVID-19 occurred in a patient with paused immunotherapy (treated before with Dimethyl Fumarate, but paused due to lymphopenia). Optic neuritis without other radiographic evidence of disease activity occurred 19 days after the PCR diagnosis of COVID-19 and was treated with a reduced dose of intravenous Methylprednisolone (500 mg/3 days) upon resolution of COVID-19 
symptoms and inflammatory blood markers. The pre-COVID-19 EDSS within our MS and NMOSD cohort was 2.4 (95\% CI 1.3-3.6) and there was no significant difference to the post-COVID-19 EDSS of 2.5 (1.3-3.7; $p=0.7$, Wilcoxon Signed Rank Test). Radiologically, new or enlarging T2-lesions on cranial MRI (cMRI) post-COVID was present in 3/10 of all RR-MS patients (no contrast enhancing lesions). We compared this MRI activity with the two preceding MRI pre-COVID ( $n=10$ patients with MRI post-COVID, $9 / 19$ had no new cMRI to date). Here $0 / 19$ had new/enlarging T2-lesions, but the differences to the post-COVID MRI were not statistically significant ( $p=0.1$; Wilcoxon Signed Rank Test). Clinically, 5/24 patients reported at least transiently a worsening of their underlying disease symptoms after COVID-19 (worsening of diplopia in 1/2 MG patients, fatigue and increase in motor disability in 5/18 MS patients).

Table 2. COVID-19 course, outcomes and specific treatments.

\begin{tabular}{|c|c|c|}
\hline Category & Subcategory & $n$ \\
\hline \multirow[t]{7}{*}{ Symptoms } & General condition deterioration & $18 / 24$ \\
\hline & Fever & $14 / 24$ \\
\hline & Dyspnea & $3 / 24$ \\
\hline & Anosmia & $7 / 24$ \\
\hline & Pneumonia & $2 / 24$ \\
\hline & ARDS & $2 / 24$ \\
\hline & Death & $0 / 24$ \\
\hline \multirow[t]{3}{*}{ Care Setting } & Outpatient & $18 / 24$ \\
\hline & Inpatient & $4 / 24$ \\
\hline & ICU & $2 / 24$ \\
\hline \multirow[t]{2}{*}{ COVID-19 treatment } & Remdesivir and Dexamethasone & $2 / 24$ \\
\hline & Dexamethasone & $3 / 24$ \\
\hline
\end{tabular}

Abbreviations: ICU: Intensive Care Unit, ARDS: acute respiratory distress syndrome.

\section{Discussion}

We here present data of COVID-19 cases of a university neuroimmunological outpatient department in Switzerland. While most of the infections with SARS-CoV-2 had a mild to moderate course, six of 24 patients needed to be hospitalized, two suffered from viral ARDS and were treated in the ICU, but no patient died. In this observational, retrospective analysis, we could demonstrate classical risk factors for a severe COVID-19 course, especially cardio-vascular risk factors [15], as $4 / 6$ patients that needed to be hospitalized had at least one of them, additionally half of the hospitalized patients were treated with B-cell depleting therapies. Viewing the immunosuppressive mode of action of these therapies, the pivotal trial data and emerging data on COVID-19 [2,6,16], our data are well in line. In cohort studies in rheumatology [16] and in MS [2], steroid use, long-term and short-term, e.g., in case of an MS relapse, is associated with a poorer COVID-19 course. In our cohort, both prednisolone-treated patients needed to be hospitalized, one in ICU; yet, both received immunosuppressive co-treatments. The influence of an infection with SARS-CoV-2 on the underlying autoimmune disorder is unclear, and to date there are no published larger studies in this regard. Infections are known triggers of MS relapses [17,18], in case of COVID-19, this needs to be further investigated. In our cohort, one relapse (optic neuritis) occurred after COVID-19 in a patient with paused immunotherapy. In the absence of a control group, we cannot compare the actual incidence of relapses in this period. In the short-term ( $<12$ months), no influence of an infection with SARS-CoV- 2 on disability progression was detectable, but its influence on long- and medium-term MS disease course is still unclear.

Since these results are based on a small, retrospective cohort, we are cautious about how we interpret these data and well aware of the biases of an observational registry. Statistical adjustments and regression analyses are not possible due to a limited number of patients. We consider these data, although well in line with other studies, more a report from direct patient care experience. As an outlook for the upcoming months, additional 
issues will arise, concerning, e.g., vaccine hesitancy in neuroimmunological patients [19], vaccine efficacy in the context of immunotherapies, and questions of booster vaccinations in immunocompromised patients [20] as well as the use of anti-spike protein antibody cocktails in patients at risk [21].

Author Contributions: Conceptualization: R.H. and M.P.; methodology: M.P. and R.H.; formal analysis: M.P.; writing—original draft preparation: M.P. and R.H.; writing—review and editing: R.H., A.C. and A.S. All authors have read and agreed to the published version of the manuscript.

Funding: This research received no external funding.

Institutional Review Board Statement: The retrospective study was conducted according to the guidelines of the Declaration of Helsinki and approved by the Cantonal Ethics Committee of Bern for the Neuroimmunology Registry Bern “NI-Registry Bern" (KEK BE 2017-01369). Because of the nature of the analysis with pseudonymised patient data using data available from clinical routine, separate informed consent was waived by the committee. This corresponds to the local legislation. For patients seen after the introduction of the general consent (February 2015), the patients' general consent status was checked before inclusion in the analysis.

Informed Consent Statement: General consent was obtained from all subjects involved in the study.

Data Availability Statement: Upon reasonable request, data are available via the corresponding author.

Conflicts of Interest: Pistor M was funded by a translational research grant by the Department of Neurology, University Hospital Bern, Switzerland to guarantee protected research time. He also received a research grant from the Swiss MS Society. Salmen A received speaker honoraria and/or travel compensation for activities with Almirall Hermal GmbH, Biogen, Merck, Novartis, Roche, and Sanofi Genzyme and research support by the Swiss MS Society. Chan A has served on advisory boards for, and received funding for travel or speaker honoraria from Actelion-Janssen, Almirall, Bayer, Biogen, Celgene, Sanofi-Genzyme, Merck, Novartis, Roche and Teva, all for hospital research funds, and received research support from Biogen, Genzyme and UCB. AC is associate editor of the European Journal of Neurology and serves on the editorial board for Clinical and Translational Neuroscience and as topic editor for the Journal of International Medical Research. Hoepner R received speaker/advisor honorary from Merck, Novartis, Roche, Biogen, Alexion, Sanofi, BristolMyers Squibb, and Almirall. He received research support within the last 5 years from Roche, Merck, Sanofi, Biogen, and Bristol-Myers Squibb. He also received research grants from the Swiss MS Society.

\section{References}

1. Louapre, C.; Collongues, N.; Stankoff, B.; Giannesini, C.; Papeix, C.; Bensa, C.; Deschamps, R.; Créange, A.; Wahab, A.; Pelletier, J.; et al. Clinical Characteristics and Outcomes in Patients with Coronavirus Disease 2019 and Multiple Sclerosis. JAMA Neurol. 2020, 77, 1079-1088. [CrossRef] [PubMed]

2. Sormani, M.P.; Rossi, N.D.; Schiavetti, I.; Carmisciano, L.; Cordioli, C.; Moiola, L.; Radaelli, M.; Immovilli, P.; Capobianco, M.; Trojano, M.; et al. Disease-Modifying Therapies and Coronavirus Disease 2019 Severity in Multiple Sclerosis. Ann. Neurol. 2021, 89, 780-789. [CrossRef] [PubMed]

3. Salter, A.; Fox, R.J.; Newsome, S.D.; Halper, J.; Li, D.K.B.; Kanellis, P.; Costello, K.; Bebo, B.; Rammohan, K.; Cutter, G.R.; et al. Outcomes and Risk Factors Associated with SARS-CoV-2 Infection in a North American Registry of Patients with Multiple Sclerosis. JAMA Neurol. 2021, 78, 699-708. [CrossRef] [PubMed]

4. Solé, G.; Mathis, S.; Friedman, D.; Salort-Campana, E.; Tard, C.; Bouhour, F.; Magot, A.; Annane, D.; Clair, B.; Masson, G.L.; et al Impact of Coronavirus Disease 2019 in a French Cohort of Myasthenia Gravis. Neurology 2021, 96, e2109-e2120. [CrossRef] [PubMed]

5. Louapre, C.; Maillart, E.; Papeix, C.; Zeidan, S.; Biotti, D.; Lepine, Z.; Wahab, A.; Zedet, M.; Labauge, P.; Tilikete, C.; et al. Outcomes of coronavirus disease 2019 in patients with neuromyelitis optica and associated disorders. Eur. J. Neurol. 2021, 28, 3461-3466. [CrossRef] [PubMed]

6. Pistor, M.; Hoepner, A.; Lin, Y.; Jung, S.; Bassetti, C.L.; Chan, A.; Salmen, A.; Hoepner, R. Immunotherapies and COVID-19 mortality: A multidisciplinary open data analysis based on FDA's Adverse Event Reporting System. Ann. Rheum. Dis. 2021, 80, 1633-1635. [CrossRef] [PubMed]

7. European Society of Clinical Microbiology and Infectious Diseases (ESCMID)_Emerging Infections Task Force (EITaF) Lean European Open Survey on SARS-CoV-2-Infected Patients (LEOSS). Available online: https://leoss.net/ (accessed on 2 August 2021).

8. EAN. The EAN NEuro-COVID ReGistrY (ENERGY). Available online: https://www.ean.org/research/registries-surveys/neurocovid-registry (accessed on 2 August 2021). 
9. Rüthrich, M.M.; Giessen-Jung, C.; Borgmann, S.; Classen, A.Y.; Dolff, S.; Grüner, B.; Hanses, F.; Isberner, N.; Köhler, P.; Lanznaster, J.; et al. COVID-19 in cancer patients: Clinical characteristics and outcome-An analysis of the LEOSS registry. Ann. Hematol. 2021, 100, 383-393. [CrossRef] [PubMed]

10. Huber, M.K.; Raichle, C.; Lingor, P.; Synofzik, M.; Borgmann, S.; Erber, J.; Tometten, L.; Rimili, W.; Dolff, S.; Wille, K.; et al. Outcomes of SARS-CoV-2 Infections in Patients with Neurodegenerative Diseases in the LEOSS Cohort. Mov. Disord. 2021, 36, 791-793. [CrossRef] [PubMed]

11. Friedli, C.; Diem, L.; Hammer, H.; Kamber, N.; Suter-riniker, F.; Leib, S.; Chan, A.; Hirzel, C.; Hoepner, R.; Salmen, A. Negative SARS-CoV-2-antibodies after positive COVID-19-PCR nasopharyngeal swab in patients treated with anti-CD20 therapies. Ther. Adv. Neurol. Disord. 2021, 14, 17562864211016641. [CrossRef] [PubMed]

12. Ritchie, H.; Ortiz-Ospina, E.; Beltekian, D.; Mathieu, E.; Hassel, J.; Macdonald, B.; Giattino, C.; Appel, C.; Rodés-Guiro, L.; Roser, M. Our World in Data-COVID Cases-Switzerland. Available online: https:/ / ourworldindata.org/coronavirus/country/switzerland (accessed on 2 August 2021).

13. Beigel, J.H.; Tomashek, K.M.; Dodd, L.E.; Mehta, A.K.; Zingman, B.S.; Kalil, A.C.; Hohmann, E.; Chu, H.Y.; Luetkemeyer, A.; Kline, S.; et al. Remdesivir for the Treatment of COVID-19-Final Report. N. Engl. J. Med. 2020, 383, 1813-1826. [CrossRef] [PubMed]

14. Group, R.C. Dexamethasone in Hospitalized Patients with COVID-19. N. Engl. J. Med. 2021, 384, 693-704. [CrossRef]

15. Collard, D.; Nurmohamed, N.S.; Kaiser, Y.; Reeskamp, L.F.; Dormans, T.; Moeniralam, H.; Simsek, S.; Douma, R.; Eerens, A.; Reidinga, A.C.; et al. Cardiovascular risk factors and COVID-19 outcomes in hospitalised patients: A prospective cohort study. BMJ Open 2021, 11, e045482. [CrossRef] [PubMed]

16. Strangfeld, A.; Schäfer, M.; Gianfrancesco, M.A.; Lawson-Tovey, S.; Liew, J.W.; Ljung, L.; Mateus, E.F.; Richez, C.; Santos, M.J.; Schmajuk, G.; et al. Factors associated with COVID-19-related death in people with rheumatic diseases: Results from the COVID-19 Global Rheumatology Alliance physician-reported registry. Ann. Rheum. Dis. 2021, 80, 930-942. [CrossRef] [PubMed]

17. Sibley, W.; Bamford, C.; Clark, K. Clinical viral infections and multiple sclerosis. Lancet 1985, 325, 1313-1315. [CrossRef]

18. Correale, J.; Fiol, M.; Gilmore, W. The risk of relapses in multiple sclerosis during systemic infections. Neurology 2006, 67, 652-659. [CrossRef]

19. Diem, L.; Friedli, C.; Chan, A.; Salmen, A.; Hoepner, R. Vaccine Hesitancy in Patients With Multiple Sclerosis Preparing for the SARS-CoV-2 Vaccination Challenge. Neurol. Neuroimmunol. Neuroinflamm. 2021, 8, e991. [CrossRef] [PubMed]

20. Hall, V.G.; Ferreira, V.H.; Ku, T.; Ierukki, M.; Majchrzak-Kita, B.; Chaparro, C.; Selzner, N.; Schiff, J.; McDonald, M.; Tomlinson, G.; et al. Randomized Trial of a Third Dose of mRNA-1273 Vaccine in Transplant Recipients. N. Engl. J. Med. 2021, 385, 1244-1246. [CrossRef] [PubMed]

21. Weinreich, D.M.; Sivapalasingam, S.; Norton, T.; Ali, S.; Pharm, D.; Gao, H.; Ph, D.; Bhore, R.; Ph, D.; Xiao, J.; et al. REGEN-COV Antibody Cocktail Clinical Outcomes Study in COVID-19 Outpatients. N. Engl. J. Med. 2021, 385, e81. [CrossRef] [PubMed] 